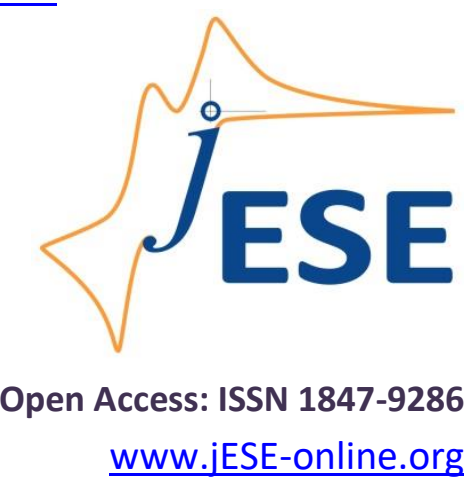

Original scientific paper

\title{
Modelling the leakage current in a solid oxide fuel cell with bi-layer electrolyte
}

\author{
Balaji Krishnamurthy ${ }^{凶}$ and Hariharan Ramasubramanian, \\ Department of Chemical Engineering, BITS Pilani, Hyderabad 500078, India \\ Corresponding author: ${ }^{\bowtie}$ balaji.krishb1@gmail.com;
}

Received: December 26, 2019; Revised: February 24, 2020; Accepted: February 24, 2020

\begin{abstract}
A mathematical model is developed to study the leakage current in a solid oxide fuel cell (SOFC) with a bi-layer electrolyte. The model predicts the variation of leakage current and power density with various design and operating factors of SOFC, namely thickness of the bi-layer electrolyte, operating temperature and operating cell voltage. The interfacial oxygen pressure in SOFC is also studied as a function of the thickness of YSZ layer. Modelling results are compared with experimental data and found to compare well.
\end{abstract}

\section{Keywords}

Anodization; pencil graphite electrode; dopamine; uric acid; ascorbic acid.

\section{Introduction}

Solid oxide fuel cells (SOFCs) are promising sources of energy due to lack of pollution and high efficiency. In order to reduce the operational temperature of SOFCs, the researchers have recently started studying SOFCs having bi-layer electrolytes. Lower operational temperatures in SOFC's reduces the corrosion rate of system components, shortens the start-up time and enables SOFCs to be used in a variety of applications [1]. Bi-layering of electrolytes is a very commonly used strategy to improve the efficiency of SOFCs with an objective of increasing interfacial oxygen pressure to improve the chemical stability of unstable electrolyte, increasing the open circuit voltage and blocking the electronic current. The electronic conductivity is viewed as arising from the following reactions:

At low oxygen pressure:

$\mathrm{O}_{0}{ }^{\mathrm{x}}=0.5 \mathrm{O}_{2}+\mathrm{V}_{0}+2 \mathrm{e}^{-}$

At medium to high oxygen pressure:

$0.5 \mathrm{O}_{2}+\mathrm{V}_{0}=\mathrm{O}_{0} \mathrm{x}+2 \mathrm{~h}$

In the fuel cell environment

$\mathrm{H}_{2}+\mathrm{O}_{0} \mathrm{x}=\mathrm{V}_{0}+\mathrm{H}_{2} \mathrm{O}+2 \mathrm{e}^{-}$ 
Shri Prakash et al. [1] have written a comprehensive review of the use of bi-layer electrolytes in SOFCs. The authors have reviewed the performance of several bi-layer electrolyte combinations. Cho at al. [2] have developed a high power density bi-layer electrolyte using gadolinium doped $\mathrm{CeO}_{2}$ (GDC) and yttria stabilized $\mathrm{ZrO}_{2}$ (YSZ) layers. The authors postulate that YSZ thin film serves as a blocking layer for preventing electrical current leakage in GDC layer and provides chemical and mechanical stability to the cell. Heidari et al. [3] have evaluated the electrochemical performance of a solid oxide fuel cell using YSZ and SDC (samaria doped ceria) bi-layer electrolyte. The authors postulate that YSZ thickness of $3.5 \mu \mathrm{m}$ ensures good chemical and mechanical stability of SOFC. Ahn et al. [4] have studied the performance of SOFC using $\mathrm{Er}_{2} \mathrm{O}_{3}$ stabilized $\mathrm{Bi}_{2} \mathrm{O}_{3}(\mathrm{ESB})$ and $\mathrm{GDC}$ bi-layer electrolyte. The authors postulate that bi-layer electrolyte can increase the open circuit potential of the cell. Further, Yahiro et al. [5] have found that a thin layer of YSZ sandwiched between the anode and YDC (yttria doped ceria) can prevent reduction of YDC and increase the open circuit potential of SOFC. Several authors [6-8] have studied the impact of thin YSZ layers effect on the blocking of the electronic current and protection of the inner layer of electrolyte.

Few mathematical models have already been developed to understand the effect of bi-layer electrolyte on the performance of SOFC. Virkar [9] has studied the oxygen partial pressure at the bilayer electrolyte interface using the equivalent circuit approach. Chen [10] developed a bi-layer electrolyte model and studied SOFC performance under different relative thicknesses. Marques and Navarro [11,12] have studied the performance of SOFCs using bi-layer electrolyte by an electrochemical permeability model. Shen et al. [13] have developed an analytical model for SOFC, based on the Nernst Planck equation. The authors have studied the variation of the interfacial oxygen pressure in the bi-layer electrolyte as a function of YSZ thickness and its effect on the performance of SOFC. Shen et al. [14] have also analysed the performance of SOFC theoretically. The authors have developed an expression for the critical thickness ratio of the bi-layer electrolyte which is essential to maintain the chemical stability of electrolyte. Chan et al. [15] have developed a model to study the performance of bi-layer electrolytes. The authors postulate that if a thin layer of YSZ is deposited onto the substrate electrolyte in the thickness ratio of 1 to 10000, it could increase the interfacial oxygen partial pressure significantly in the bi-layer electrolyte and reduce the penetration of electronic current. Studying the factors which influence the leakage current is very important in understanding the efficiency of SOFC. Several factors influence the leakage current in SOFC such as thickness of YSZ layer, temperature, voltage, ionic conductivity ratios of the bi-layer electrolyte, electronic conductivity ratios of the bi-layer electrolyte, etc. Since the leakage current significantly affects the power density of SOFC, studying the effect of these parameters on the leakage current and power density in addition to the interfacial oxygen pressure in the bi-layer electrolyte, is very important in understanding the overall performance of SOFC. Some of the earlier papers have studied the effect of YSZ thickness on the power density and interfacial oxygen pressure in a bi-layer SOFC. However, a study of some of the parameters which affect the leakage current in SOFC with bi-layer electrolyte (especially effects of applied voltage, temperature, ionic conductivity ratio and electronic conductivity ratio of the bi-layer electrolyte) has not been studied by any previous model. In this paper, we have tried to address just these effects.

\section{Model development and assumptions}

Figure 1 shows the schematic of SOFC with a bi-layer electrolyte. The total thickness of the bilayer electrolyte is given by $t\left(t_{1}+t_{2}\right)$. The model considers gadolinia doped ceria (GDC) as the substrate electrolyte coated with a thin layer of yttria stabilized zirconia (YSZ) on the anode side. 
The migration of the oxygen ions and diffusion of electron holes and electrons lead to the creation of leakage current (electronic current).

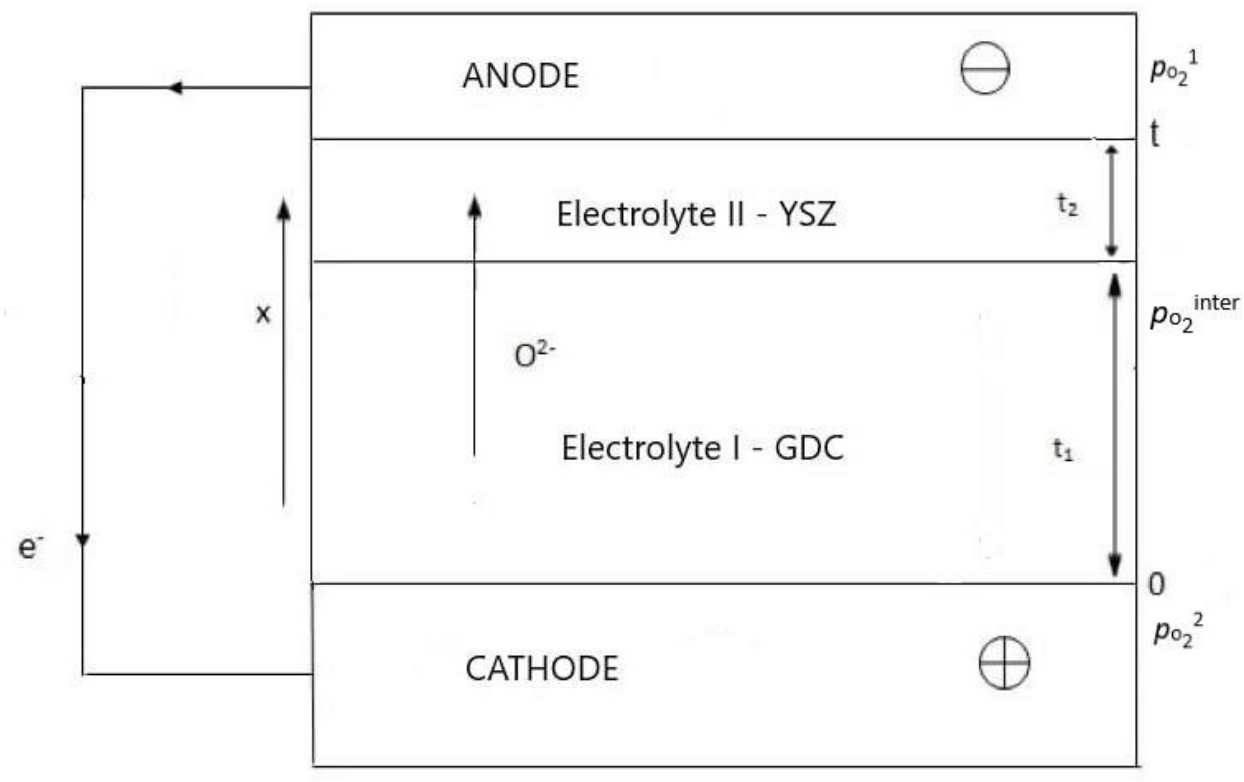

Figure 1. Schematic of the bi-layer electrolyte SOFC

\section{Model assumptions}

a. The electronic current is assumed to be due to the transport of oxygen vacancies and electrons through the electrolytes.

b. Ionic and electronic current densities in the two electrolytes are assumed continuous across the electrolytes.

c. The contact resistance between the electrolytes is assumed small and there is no reaction between electrolytes.

d. The cell is assumed to operate isothermally.

The concentration and activation overpotentials are neglected in the model.

Model equations

The flux of the species in the bi-layer electrolyte is represented by the Nernst Planck equation

$$
J_{\mathrm{i}}=-z_{\mathrm{i}} u_{\mathrm{i}} F c_{\mathrm{i}} \nabla \phi-D_{\mathrm{i}} \nabla c_{\mathrm{i}}
$$

where $J_{i}$ is the mole flux of the charge $\left(\mathrm{O}^{2-}\right.$ and $\left.e^{-}\right)$. The first term on the right-hand side is the migration term. Here $\phi$ refers to the electrostatic potential (the gradient of the electrostatic potential is used in the equation) and $c_{i}$ refers to the concentration of species $i$.

The current arising from the motion of the charged particles is defined as:

$\left.I=F \sum z_{\mathrm{i}}\right\rfloor_{\mathrm{i}}$

For electroneutral electrolyte, the following equation is valid:

$\sum z_{\mathrm{i}} c_{\mathrm{i}}=0$

The electronic conductivity in this model is assumed to obey $1 / n$ power law of oxygen partial pressure where $n=-4$ while the ionic conductivity is constant for the electrolyte. Thus $[13,14]$,

$\sigma_{\mathrm{e}}=\sigma_{\mathrm{e}}^{0} p_{\mathrm{O}_{2}}{ }^{-1 / 4}$ 
where $\sigma_{\mathrm{e}}{ }^{0}$ is a coefficient which depends only on temperature. The ionic conductivities of two electrolytes are denoted as $\sigma_{0^{2-}}{ }^{-1}$ and $\sigma_{0^{2-}}{ }^{-1}$, respectively. Similarly, electronic conductivities are denoted as $\sigma_{\mathrm{e}}^{\prime}$ and $\sigma_{\mathrm{e}}^{\prime \prime}$, respectively.

Using the species concentration equations developed by Shen et al. [13,14], the following expressions for ionic and electronic current densities can be found by applying transport equations:

$$
i_{\mathrm{O}^{2-}}=\frac{\sigma_{\mathrm{O}^{2-}}{ }^{\mathrm{eq}}\left(V_{t} h-V\right)}{t} i_{\mathrm{e}}=\sigma_{\mathrm{O}^{2-}} \mathrm{eq}\left(\frac{V_{\mathrm{th}}-V}{t}\right)\left(\frac{R_{1}\left(p_{\mathrm{O}_{2}}{ }^{1}\right)^{-\frac{1}{4}}-\frac{1}{R_{2}}\left(p_{\mathrm{O}_{2}}{ }^{2}\right)^{-\frac{1}{4}}}{\left(R_{1}-1\right)\left\{\frac{\sigma_{\mathrm{O}^{2-}}{ }^{1}}{\sigma_{\mathrm{e}}{ }^{1}}\right\}+\left(1-\frac{1}{R_{2}}\right)\left\{\frac{\sigma_{\mathrm{O}^{2-}}}{\sigma_{\mathrm{e}}{ }^{11}}\right\}}\right)
$$

where $t$ is the total thicknesses of the electrolyte (both electrolyte 1 and electrolyte 2). The equivalent ionic conductivity is defined as [13-15]

$$
\sigma_{\mathrm{O}^{2-}}{ }^{\mathrm{eq}}=\frac{t}{t_{1} / \sigma_{\mathrm{O}^{2-}}{ }^{1}+t_{2} / \sigma_{\mathrm{O}^{2-}}{ }^{11}}
$$

where $t_{1}$ and $t_{2}$ are the thickness of electrolyte 1 and electrolyte 2 , respectively.

Thus, the relationship between total current and operating voltage for SOFCs with a bi-layer electrolyte can be written as:

$$
i_{\text {total }}=t_{\mathrm{O}^{2-}}+t_{\mathrm{e}}
$$

Substituting eqs. (5) and (6) into eq. (8), gives

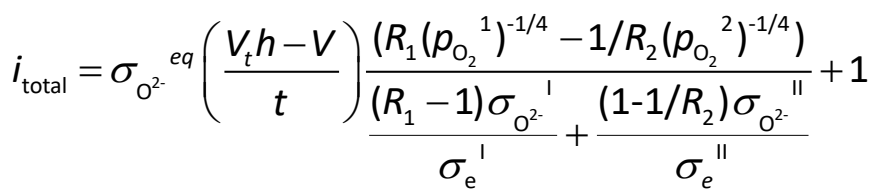

where

$$
\begin{aligned}
& R_{1}=\exp \left(\frac{-t_{1} \sigma_{\mathrm{O}^{2 \cdot}}{ }^{\text {eq }}}{\sigma_{\mathrm{O}^{2 \cdot}}{ }^{1}} \frac{V_{t} h-V}{T} \frac{q}{k_{\mathrm{B}} T}\right) \\
& R_{2}=\exp \frac{-t_{2} \sigma_{\mathrm{O}^{2-}}{ }^{\mathrm{eq}}}{\sigma_{O^{2-}}{ }^{11}} \frac{V_{t} h-V}{T} \frac{q}{k_{\mathrm{B}} T}
\end{aligned}
$$

and

$$
V_{\text {th }}=\frac{k_{\mathrm{B}} T}{4 q} \ln \frac{p_{\mathrm{O}_{2}}{ }^{\prime \prime}}{p_{\mathrm{O}_{2}}{ }^{\prime}}
$$

Expression (12) translates current density as a function of the operating voltage. When the partial pressures of oxygen at the electrodes are known, the total current density can be calculated directly using eq. (8). Also, the output power density can be determined as:

$P=i_{\text {total }} V$

The efficiency of SOFC can be calculated as

$$
\eta=\frac{V}{V_{\text {th }}} \frac{i_{\text {total }}}{i_{\mathrm{o}^{2}}}
$$

The distribution of the oxygen partial pressure across the bi-layer electrolyte is given as [13-15] 


$$
\begin{aligned}
& p_{O_{1}}(x)^{-1 / 4}=c_{1}\left(p_{O_{2}}{ }^{1}\right)^{-1 / 4}-\left(c_{1}-1\right) i_{\mathrm{e}} / i_{\mathrm{O}^{2 \cdot}}\left(\sigma_{\mathrm{O}^{2-}}{ }^{\prime}\right) /\left(\sigma_{e}{ }^{\prime}\right) \quad\left(0 \leq x \leq t_{1}\right) \\
& p_{\mathrm{O}_{2}}(x)^{-1 / 4}=\frac{1}{c_{2}\left(p_{\mathrm{O}_{2}}{ }^{2}\right)^{-1 / 4}} /-\frac{c_{2}-1}{c_{2}} \frac{i_{\mathrm{e}}}{i_{\mathrm{O}^{2-}}} \frac{\sigma_{O^{2-}}{ }^{\prime \prime}}{\sigma_{e}}\left(t_{1} \leq x \leq t\right)
\end{aligned}
$$

where

$$
\begin{aligned}
& c_{1}=\exp \left\{\frac{-i_{\mathrm{O}^{2-}}}{\sigma_{\mathrm{O}^{2-}}} \frac{q}{k_{\mathrm{b}} T} x\right\} \\
& c_{2}=\exp \left(\frac{-i_{\mathrm{O}^{2-}}}{\sigma_{\mathrm{O}^{2-}} 1 \frac{q}{k_{b} T}}(t-x)\right)
\end{aligned}
$$

The equations for leakage current density (eq. (9)) and interfacial oxygen partial pressures (eqs. (20) and (21)) are solved using MATLAB.

\section{Results and discussion}

Table 1 shows the list of parameters used for all simulations presented in Figures 2-12.

Table 1. Parameters used for calculations.

\begin{tabular}{ccccccc}
\hline \multirow{2}{*}{$T / \mathrm{K}$} & \multirow{2}{*}{$p^{1} / \mathrm{atm}$} & \multirow{2}{*}{$p^{2} / \mathrm{atm}$} & \multicolumn{2}{c}{$\mathrm{GDC}$} & \multicolumn{2}{c}{$\mathrm{YSZ}$} \\
\cline { 4 - 7 } & & $\sigma_{02-} / \mathrm{S} \mathrm{cm}^{-1}$ & $\sigma_{e}^{0} / \mathrm{S} \mathrm{cm}^{-1}$ & $\sigma_{0^{2-}} / \mathrm{S} \mathrm{cm}^{-1}$ & $\sigma_{e}^{0} / \mathrm{S} \mathrm{cm}^{-1}$ \\
\hline 1073 & $10^{-14}$ & 0.21 & 0.075 & $7.16 \times 10^{-6}$ & 0.022 & $7.16 \times 10^{-10}$ \\
\hline 1023 & $10^{-14}$ & 0.1 & 0.0741 & $3.83 \times 10^{-6}$ & 0.0148 & $3.83 \times 10^{-10}$ \\
\hline 973 & $10^{-14}$ & 0.1 & 0.0471 & $5.01 \times 10^{-7}$ & 0.006 & $5.01 \times 10^{-11}$ \\
\hline
\end{tabular}

Figure 2 shows simulations of the variation of leakage current density with increasing thickness of YSZ layer (up to $0.15 \mu \mathrm{m}$ ) at three temperatures $(1073,1023$, and $973 \mathrm{~K}$ ). The figure shows that the addition of YSZ bi-layer decreases the leakage current at all three temperatures. It is also seen that for the given set of parameters, the leakage current decreases with increase in the thickness of YSZ layer until $0.05 \mu \mathrm{m}$, and then levels off. Increasing thickness of YSZ layer increases the overall cell resistance and leads to voltage losses in the cell. Therefore, an optimum thickness of YSZ thickness is required for enhanced power density. In their work, Chan et al. [15] postulated that YSZ layer having thicknesses in the range from 0.1 to $1 \mu \mathrm{m}$ can effectively protect the substrate electrolyte and enhance the power density of the cell.

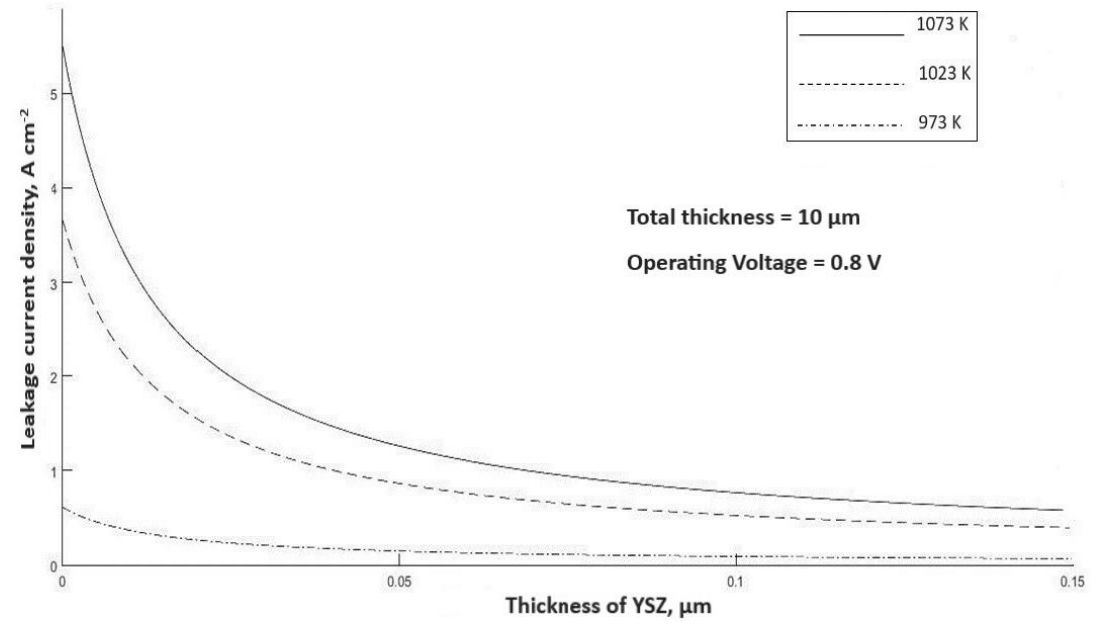

Figure 2. Variation of leakage current density in SOFC with thickness of YSZ layer at different temperatures

Simulation results presented in Figure 2 indicate that YSZ layer thickness of $0.05 \mu \mathrm{m}$ reduces the leakage current significantly and enhances the power density. The leakage current is also seen to 
increase with increase in temperature. The leakage current or the electronic current primarily happens because of diffusion of electrons and electron-holes across the electrolyte layer. The increase of temperature increases diffusion of these electrons and electron holes across the electrolyte layer thus increasing the leakage current.

Figure 3 shows the variation of leakage current density with the thickness of YSZ layer for varying values of cell voltage $(0.6,0.7$ and $0.8 \mathrm{~V})$. It is seen that the leakage current density is higher at increasing cell voltages. The increasing cell potential across SOFC creates an additional driving force for the transport of electrons and electron holes across the bi-layer electrolyte leading to an increase in the leakage current.

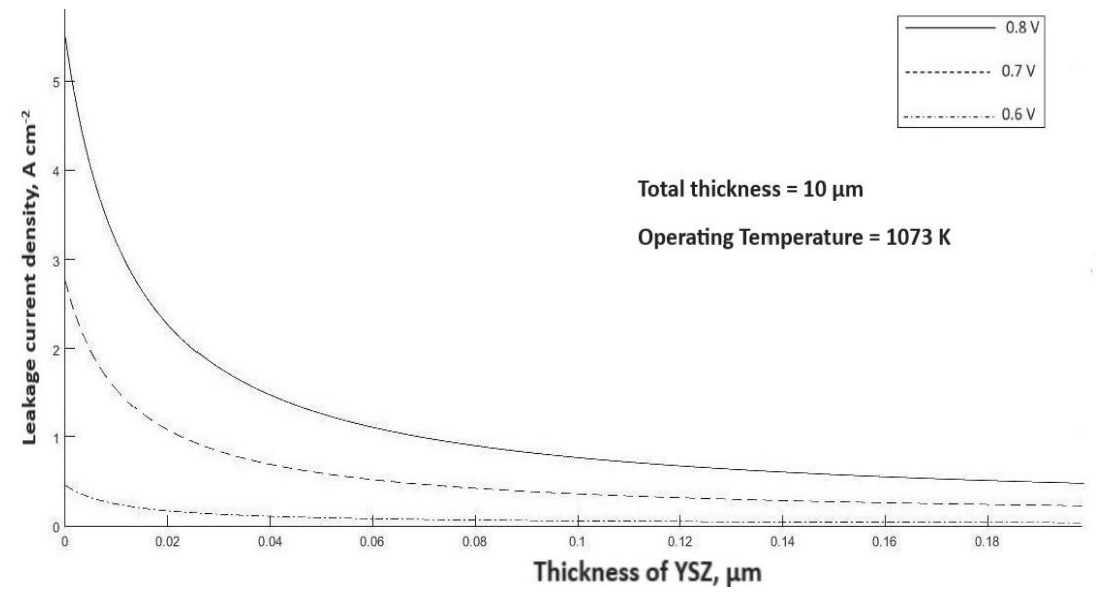

Figure 3. Variation of leakage current density in SOFC with thickness of YSZ layer for different voltages applied across the cell

Figure 4 shows the variation of the cell power density with the thickness of YSZ layer for three different temperatures. The figure shows that the overall cell power density increases with increase of temperature. At the beginning, the cell power density is seen to increase with addition of YSZ layer, but when the thickness of the YSZ layer becomes higher than $0.05 \mu \mathrm{m}$, the power density is seen to decrease slowly. It seems that increase of the ohmic resistance introduced by addition of YSZ layer and the associated voltage drop cause reduction of power density. Thus, it is very important to optimize the thickness of YSZ layer to obtain the maximum power density in SOFC.

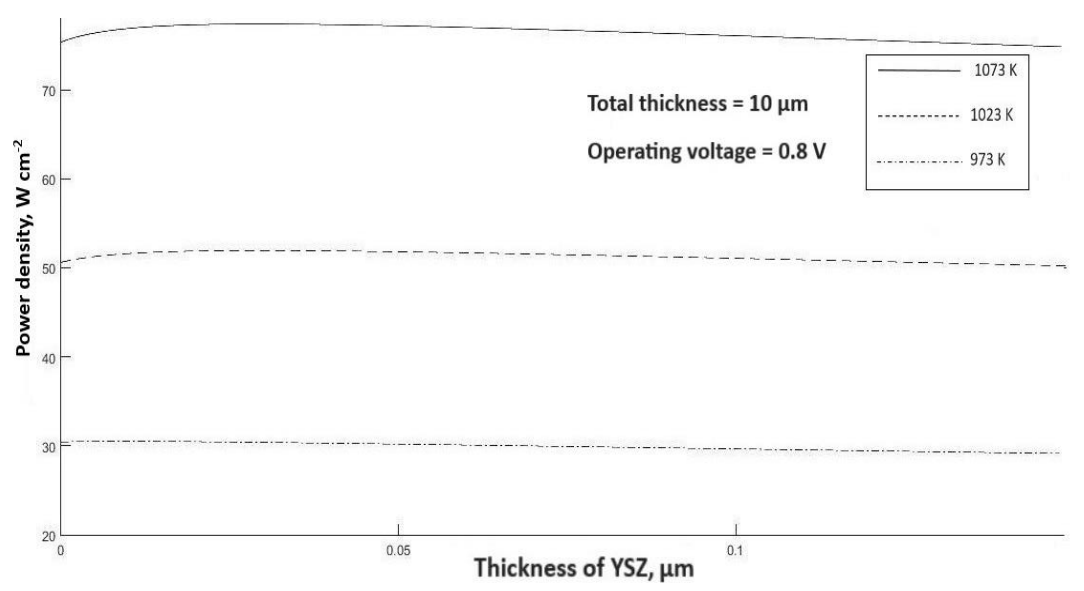

Figure 4. Variation of power density of SOFC with thickness of YSZ layer at different temperatures

Figure 4 is supported by Figure 5 which shows the variation of power density with thickness of the YSZ layer (variation of voltage). The figure clearly shows the peak power density occurring at a YSZ thickness ranging from $0.02 \mu \mathrm{m}$ to $0.05 \mu \mathrm{m}$. 


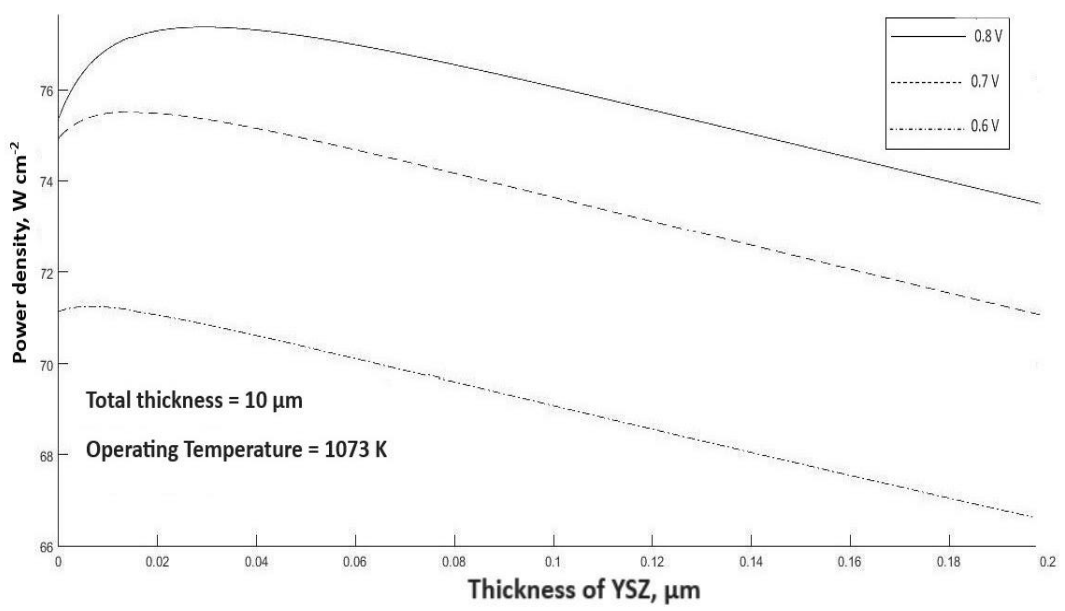

Figure 5. Variation of power density of SOFC with thickness of YSZ layer for different voltages applied across the cell

Figure 6 shows the variation of leakage current density with YSZ thickness for different electronic conductivity ratios of GDC:YSZ layer. The electronic conductivity ratio of two layers is varied as 1 : $0.1,1: 0.01$ and 1:0.001. The total thickness of the bi-layer electrolyte is kept at $10 \mu \mathrm{m}$ and the thickness of YSZ layer is varied from 0 to $0.05 \mu \mathrm{m}$. The leakage current is found to vary significantly with decreasing values of electronic conductivity of YSZ layer. It is seen that the lowest leakage current is obtained when the ratio is 1:0.001, indicating that the electronic conductivity of the additional layer should be much lower than the primary layer. Typically the electronic conductivity of YSZ layer is seen to be lower than GDC layer by value of 0.01 to 0.001 . It is seen that when the electronic conductivity of YSZ layer is significantly lower compared to GDC layer, the leakage current is found almost negligible even at every low thickness of YSZ layer.

Figure 7 shows the corresponding variation of power density with electronic conductivity of the GDC: YSZ layers varying in the same ratio. From Figure 5, we see the highest power densities corresponding to the lowest leakage current density graphs. For 1:0.001 ratio of electronic conductivities of GDC: YSZ, the peak power density is seen for YSZ thickness of $0.02 \mu \mathrm{m}$. Thus, it is important to use an additional layer with lower value of electronic conductivity since it minimizes the thickness of electrolyte required to minimize leakage current. This consequently reduces the ohmic drop and the voltage drop across the cell improving the power density.

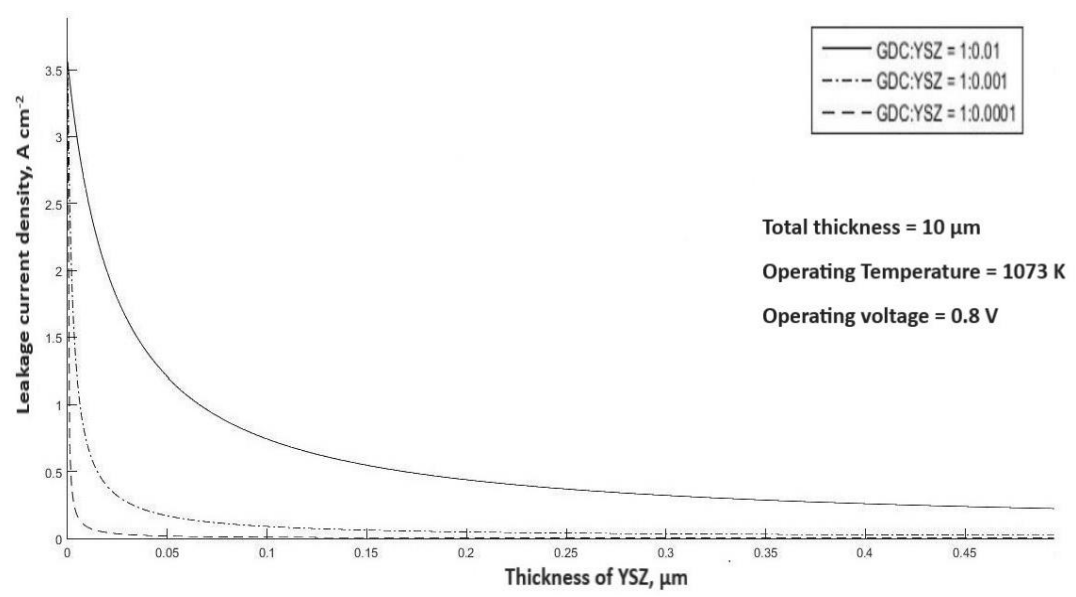

Figure 6. Variation of leakage current density of SOFC with thickness of YSZ layer for different electronic conductivity ratios of GDC:YSZ layer

It is seen in Figure 8 that varying ionic conductivities of bi-layer electrolyte affects the leakage current but not to the extent of the electronic conductivity (cf. Fig. 6). It is seen that when YSZ has 
the lowest ionic conductivity compared to GDC, the leakage current is the lowest showing the effect of ionic conductivity on the leakage current.

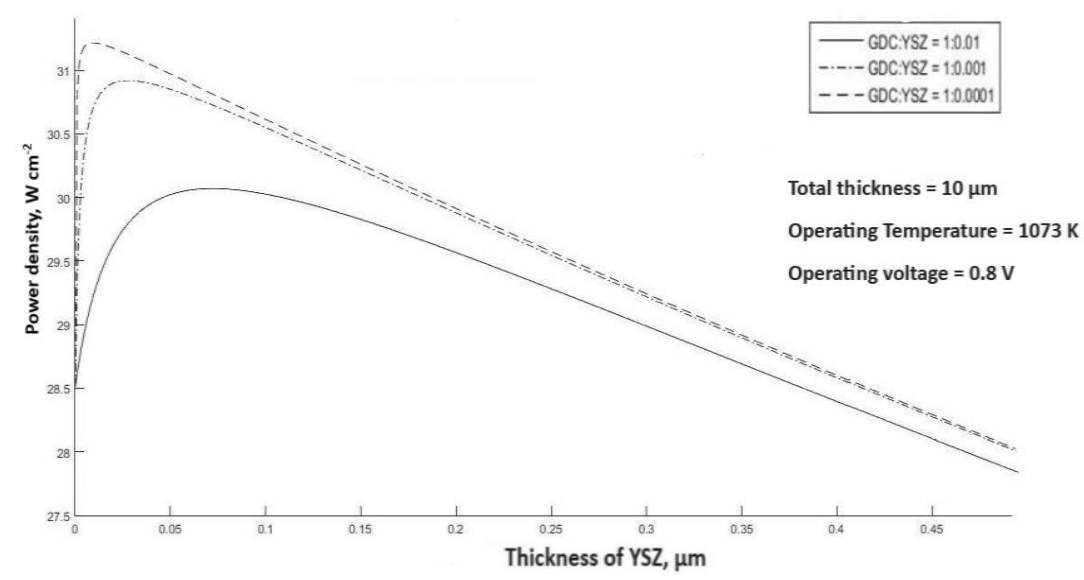

Figure 7. Variation of power density of SOFC with thickness of YSZ for different electronic conductivity ratios of GDC: YSZ layer

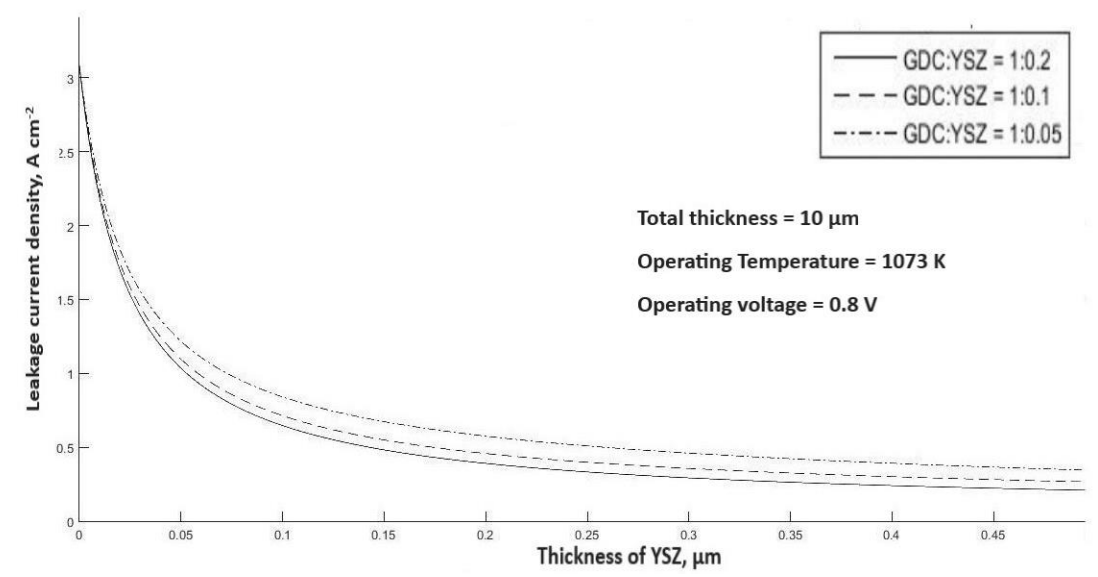

Figure 8. Variation of the leakage current density of SOFC with thickness of YSZ for different ionic conductivity of YSZ layer

Figure 9 shows the corresponding power densities in a bi-layer SOFC for variation of ionic conductivities. It is seen that changing of ionic conductivities has a substantial effect on the power densities. While the leakage current does not change substantially, the change in the power density of the bi-layer SOFC seems to be substantial with change of the ionic conductivity

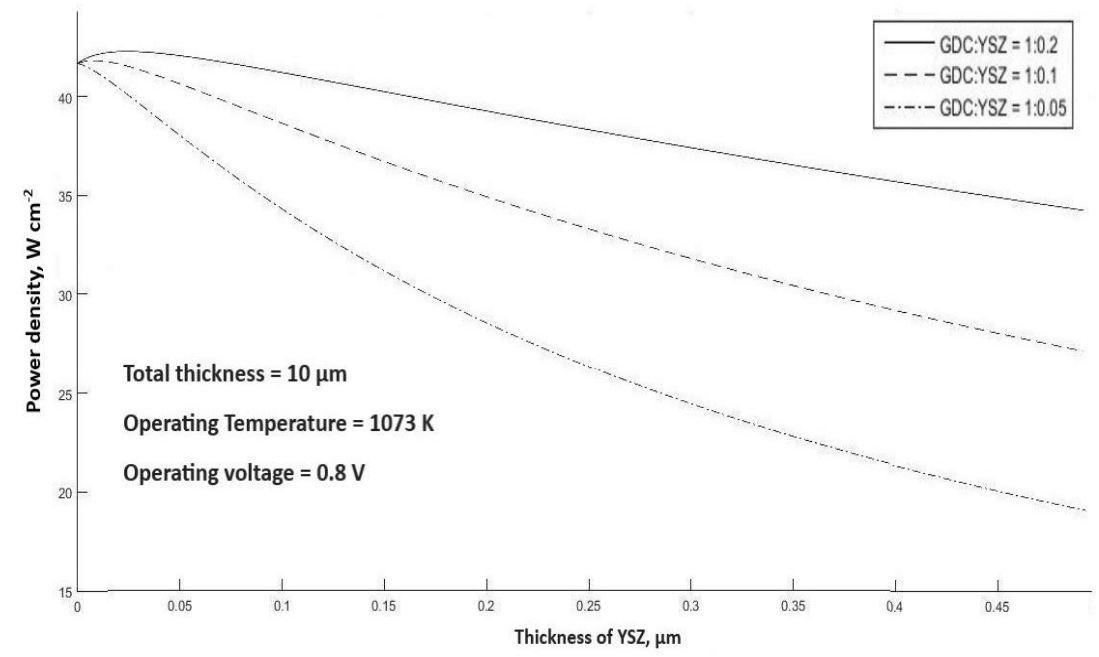

Figure 9. Variation of power density of SOFC with thickness of YSZ for different ionic conductivities of YSZ layer 
Owing to the increase in the ionic conductivity of YSZ layer, the electrical resistance of the YSZ layer decreases, which leads to a substantial increase in the power density. It is known that in bilayer electrolyte in SOFC, the inner electrolyte near the cathode can be unstable. To protect the unstable electrolyte near the cathode, the oxygen partial pressure at the interface of the bi-layer electrolyte must always be higher than its decomposition oxygen partial pressure [13-15]. Thus predicting the interfacial oxygen pressure in a bi-layer electrolyte SOFC becomes critical.

Figure 10 shows the interfacial oxygen partial pressure vs. distance along the electrolyte for different thicknesses of YSZ layer. While the thickness of GDC layer is kept at $2.5 \mu \mathrm{m}$, the thickness of YSZ layer is varied from 0.02 to $0.08 \mu \mathrm{m}$. The interfacial oxygen partial pressure is seen to rise steeply at the interface of GDC/YSZ. It is also seen that the partial pressure in YSZ layer increases with increasing thickness of YSZ layer.

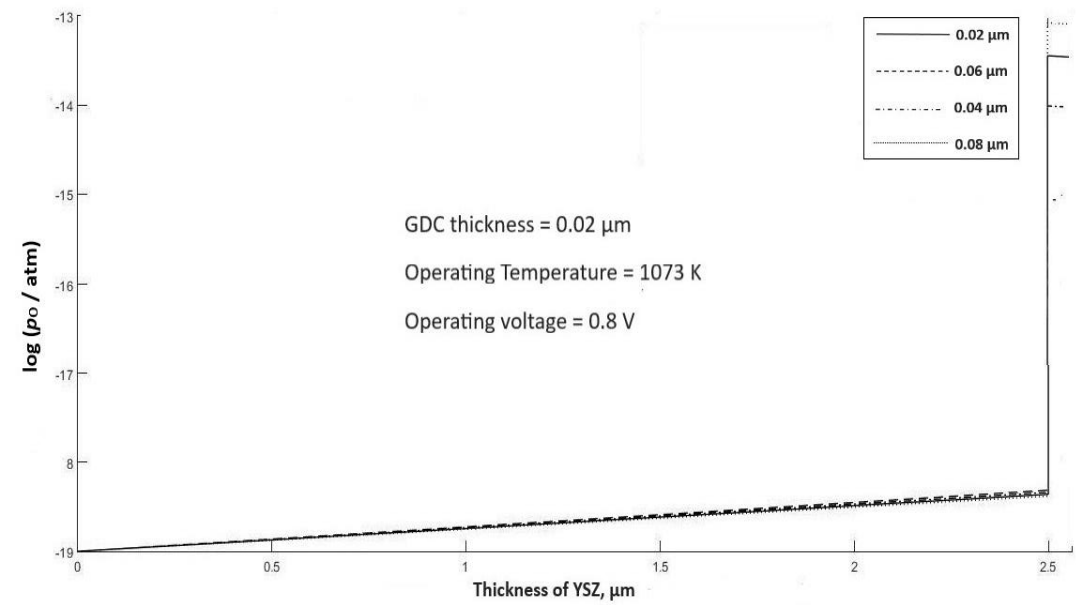

Figure 10. Variation of interfacial oxygen pressure in SOFC as a function of thickness of YSZ layer

Thus, while we see that the power density is the highest when YSZ layer is around $0.02 \mu \mathrm{m}$, the corresponding oxygen partial pressure is low. Therefore, the thickness of YSZ layer has to be optimized to get the maximum power density and also to enhance the interfacial oxygen partial pressure. Simulation results indicate that the ideal thickness of YSZ layer would be between 0.02 to $0.1 \mu \mathrm{m}$. Chan [15] has predicted that for a substrate electrolyte thickness varying from 100 to $1 \mathrm{~mm}$, a layer of YSZ with thickness of 0.1 to $1 \mu \mathrm{m}$ can effectively protect the substrate electrolyte and maintain a high current density in the cell. It is found that for the given set of parameters, thicknesses of 0.02 to $0.1 \mu \mathrm{m}$ of YSZ layer give the best power output and interfacial oxygen pressure.

Figure 11 shows the interfacial oxygen pressure as a function of distance along the electrolyte for different thickness ratios of GDC:YSZ layer. The graph clearly shows that with decreasing thickness of YSZ layer, the interfacial oxygen pressure decreases which corresponds to the graph in Fig. 10.

Figure 12 shows the graphs of interfacial oxygen pressure as a function of distance along the electrolyte at different temperatures. It is seen that the interfacial oxygen partial pressure increases with increase in temperature. However, it is not possible to conclude that the stability of the unstable electrolyte increases with increase in temperature, since the stability of the electrolyte depends on other operating conditions as well.

Figure 13 shows the comparison of modelling predictions with experimental data (polarization curve taken from ref. [17]. Since the conductivity values of GDC and SDC are very close [13], we have modelled the polarization curve of a bi-layer electrolyte SOFC using YSZ (318 $\mu \mathrm{m})$ and SDC (737 $\mu \mathrm{m})$ at $650^{\circ} \mathrm{C}$. The list of parameters based on experimental data $[13,17]$ are used and shown in Table 2. Modelling results are found to compare very well with experimental data. 


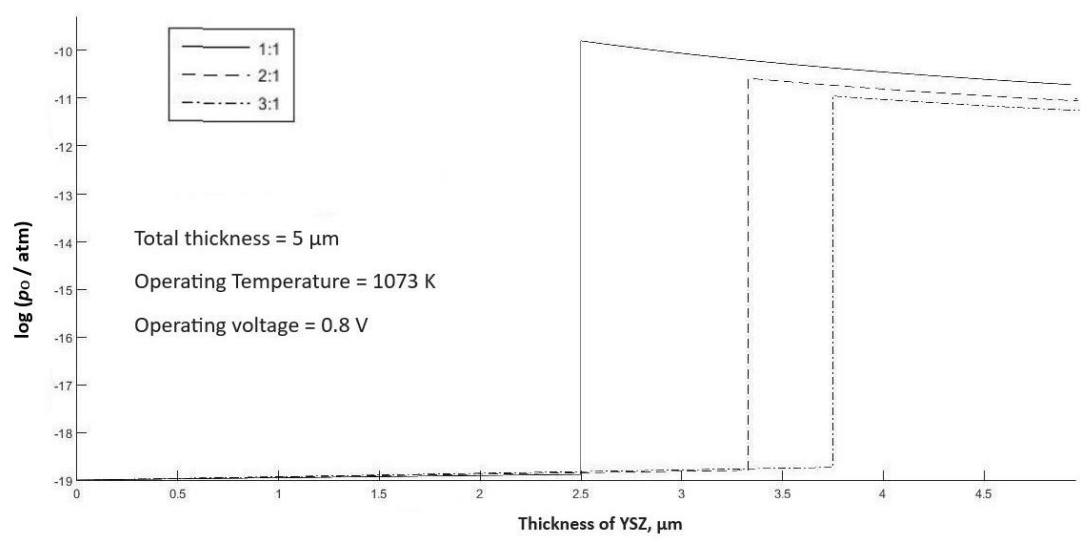

Figure 11. Variation of the interfacial oxygen pressure with distance along the electrolyte in SOFC for different thickness ratio of GDC: YSZ layer

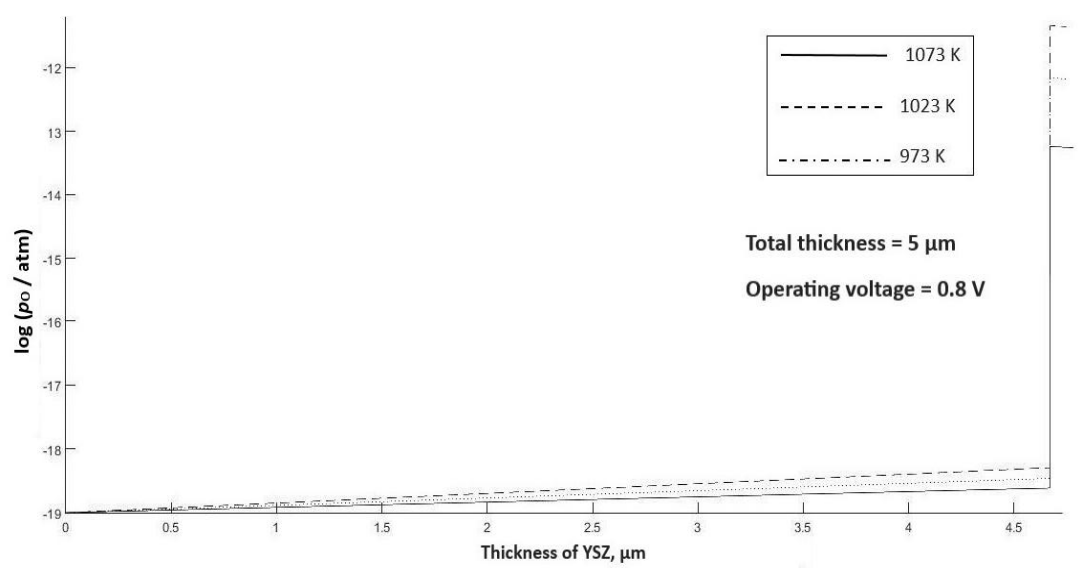

Figure 12. Variation of the interfacial oxygen pressure in SOFC with distance along the electrolyte at different temperatures

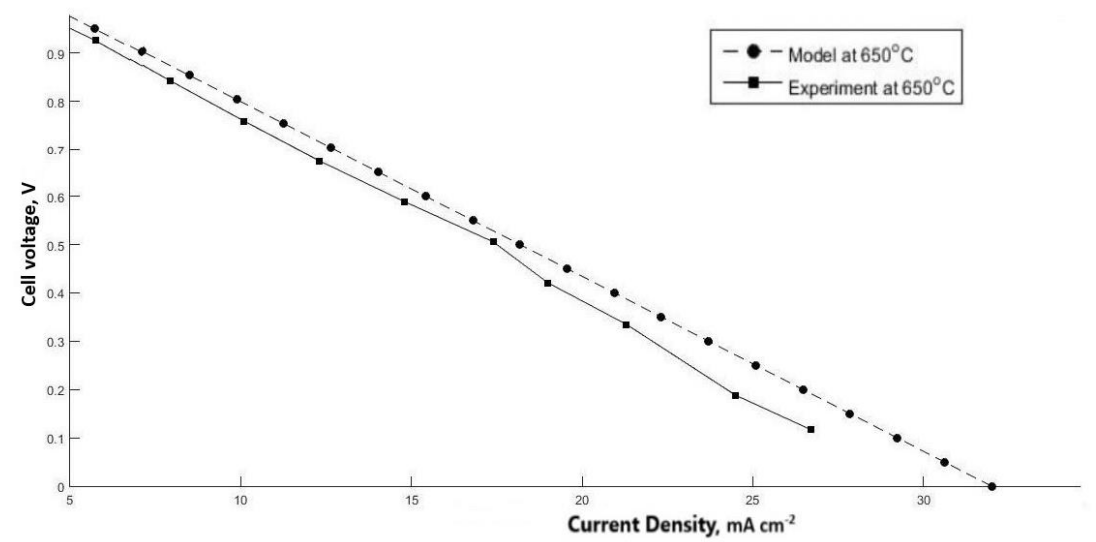

Figure 13. Comparison of polarization curves obtained by modelling predictions and experiment [17]

Table 2. List of parameters used for calculation of polarization curve in Figure 13.

\begin{tabular}{lc}
\hline Parameter & Value \\
\hline SDC ionic conductivity, S/cm & 0.019 \\
\hline SDC co-eff of electronic conductivity, S/cm & $8.21 \times 10-8$ \\
\hline YSZ ionic conductivity, S/cm & 0.003 \\
\hline YSZ co-eff of electronic conductivity, S/cm & $8.21 \times 10-10$ \\
\hline YSZ thickness, $\mu \mathrm{m}$ & 318 \\
\hline SDC thickness, $\mu \mathrm{m}$ & 737 \\
\hline Total thickness, $\mu \mathrm{m}$ & 1055 \\
\hline Temperature, $\mathrm{K}$ & 923 \\
\hline
\end{tabular}




\section{Conclusion}

The effect of design and operational parameters on the leakage current of a bilayer SOFC (specifically GDC: YSZ bilayer) is modelled. Simulation results indicate that for the given set of operating parameters, the peak power density is seen for YSZ film thickness of 0.02 to $0.08 \mu \mathrm{m}$. The leakage current is seen to decrease with increasing thickness of YSZ layer at various temperatures and cell voltages. The power density is seen to reach a maximum value with increasing thickness of YSZ layer at various temperatures and cell voltages. However, increasing thickness of YSZ layer is seen to reduce the power density, showing the effect of ohmic resistance. The ionic conductivity of YSZ layer is found to play a minimal role, while the electronic conductivity of YSZ layer is found to play a significant role in determining the leakage current. When the ratio of YSZ:GDC electronic conductivity is low, the leakage current is found to be correspondingly low. The interfacial oxygen pressure which plays a major role in determining the stability of the inner electrolyte is found to increase with increasing thickness of YSZ layer and is also found to increase with temperature. Thus, it can be seen that the thickness of YSZ layer has to be optimized to enhance the power density in a bi-layer SOFC.

\section{Nomenclature}

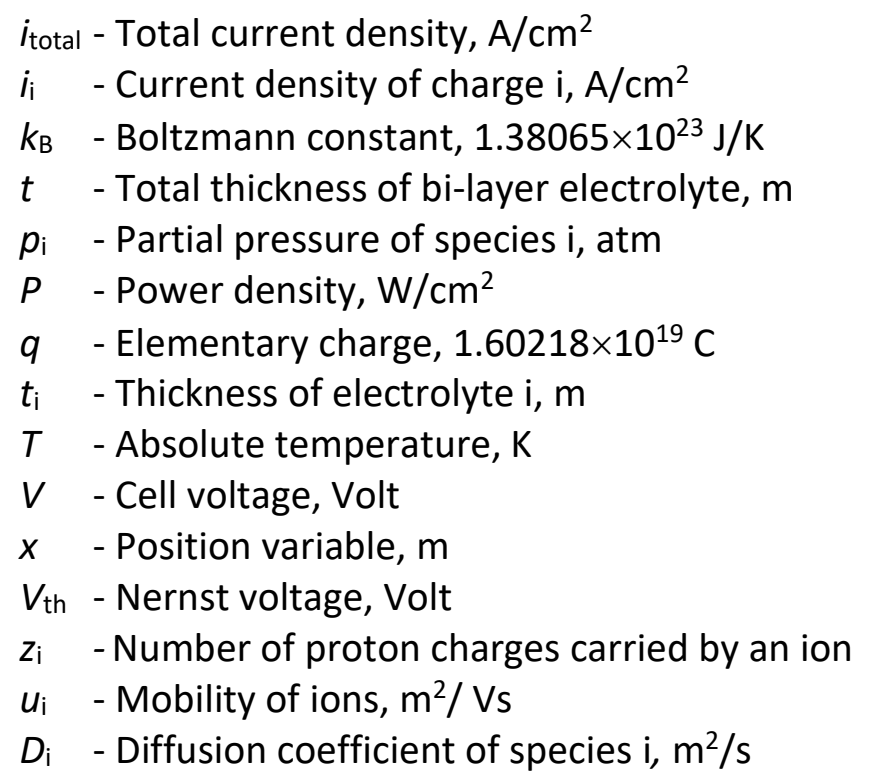

Subscripts

$\mathrm{O}_{2}$ - Oxygen

$\mathrm{O}^{2-}$ - Oxygen ion

$e^{-}-$Electron

Int - Measured interfacial parameters

Superscripts

1 - anode parameters

2 - cathode parameters

I, II - electrolyte 1 or electrolyte 2

Greek letter

$\eta$ - Efficiency of SOFC

$\sigma$ - Conductivity, $\mathrm{S} / \mathrm{m}$

Acknowledgements: The authors wish to acknowledge BITS Pilani, Hyderabad for the support given for this article. 


\section{References}

[1] B. Shri Prakash, R. Pavitra, S. Senthil Kumar, S. T. Aruna, Journal of Power Sources 381 (2018) 136155.

[2] S. Cho, Y. N. Kim, J.-H. Kim, A. Manthiram, H. Wang, Electrochimica Acta 56 (2011) 5472-5477.

[3] D. Heidari, S. Javadpour, S. H. Chan, Energy Conversion and Management 150 (2017) 567-573.

[4] J. S. Ahn, M. A. Camaratta, D. Pergolesi, K. T. Lee, H. Yoon, B. W. Lee, D. W. Jung, E. Traversa, E. D. Wachsman, Journal of the Electrochemical Society 157 (2010) B376-B382.

[5] H. Yahiro, Y. Baba, K. Eguchi, H. Arai, Journal of the Electrochemical Society 135 (1988) 2077-2080.

[6] K.-W. Chour, J. Chen, R. Xu, Thin Solid Films 304 (1997) 106-112.

[7] T. Tsai, E. Perry, S. Barnett, Journal of the Electrochemical Society 144 (1997) L130-132.

[8] K. Mehta, R. Xu, A.V. Virkar, Journal of Sol-Gel Science and Technology 11 (1998) 203-207.

[9] 9. A. V. Virkar, Journal of the Electrochemical Society 138 (1991) 1481.

[10] Z. Chen, Journal of the Electrochemical Society 151 (2004) A1576-1583.

[11] F. M. B. Marques, L. M. Navarro, Solid State lonics 100 (1997) 29-38.

[12] F. M. B. Marques, L. M. Navarro, Solid State lonics 90 (1996) 183-92.

[13] S. Shen, L. Guo, L. Liu, International Journal of Hydrogen Energy 38 (2013) 1967-1975.

[14] S. Shen, L. Guo, H. Liu, International Journal of Hydrogen Energy 38 (2013) 13084-13090.

[15] S. H. Chan, X. J. Chen, K. A Khor, Solid State lonics 158 (2003) 29-43.

[16] J. L. Sepulveda, S. Chang, R. O. Loutfy, in: Advances in solid oxide fuel cells IV, P. Singh, N. P. Bansal, T. Obji, A. Wereszczak (Eds.), Wiley, USA, Vol. 29 (5), 2009, p. 216.

[17] S. Shen, L. Guo, H. Liu, International Journal of Hydrogen Energy 41 (2016) 3646-3654.

C 2020 by the authors; licensee IAPC, Zagreb, Croatia. This article is an open-access article distributed under the terms and conditions of the Creative Commons Attribution license (http://creativecommons. org/licenses/by/4.0/) 